\title{
La expresión en la escritura de Imre Kertész*
}

\author{
The expression of Imre Kertész's writing
}

\author{
Jaime Aspiunza \\ Universidad del País Vasco, San Sebastián, España, \\ e-mail: jaspiunza@yahoo.com
}

La obra literaria de Imre Kertész, siendo obra de ficción, tiene un marcado carácter autobiográfico, hasta el punto de que al respecto se ha hablado de "novela autobiográfica". El, sin embargo, rechaza tal rótulo: "¡tal género no existe!”, dice. Se plantea así -y la totalidad de su obra no hace sino confirmar la importancia de tal cuestión- el problema de cómo entender su escritura: ¿Qué relación hay entre escritura o lenguaje y experiencia? ¿Y entre lenguaje y mundo? -Nos parece que las ideas y la práctica literaria de Kertész sólo pueden entenderse en el marco de lo que suele llamarse pensamiento fenomenológico-hermenéutico. Con la ayuda de algunas nociones tomadas de Nietzsche, Heidegger y Merleau-Ponty, se intentará exponer lo que sería un concepto no mimético (ni subjetivo) de expresión.

Palabras clave: Kertész, expresión, lenguaje, existencia, mundo, Auschwitz, hermenéutica, fenomenología.

Imre Kertész's literary work has a predominant autobiographical character, being at the same time a work of fiction. His have been said to be "autobiographical novels". The author rejects, however, this label: "such a gender does not exist!", he says. The problem is -and his whole work only confirms the significance of this question- how to understand his writing: What is the relationship between writing, or language, and experience? And the relationship between language and world? -This work states that Kertész's ideas and the literary practice can only be well understood in the frame of a so-called hermeneutical-phenomenological thought. With the help of some basic ideas borrowed from Nietzsche, Heidegger, and Merleau-Ponty, this study will try to explain what it could be called a non-mimetical (and non-subjective) concept of expression.

Key words: Kertész, expression, language, existence, world, Holocaust, hermeneutics, phenomenology.

\footnotetext{
* Este texto ha sido escrito en el marco de los proyectos de investigación "La expresión de la subjetividad en las artes", dirigido por F. Pérez Carreño (MEC "HUM-2005-2533/FISO"), y "El testimonio en los genocidios del siglo XX. Una investigación estética”, dirigido por C. Martínez Gorriarán (EHU06/79).
} 
1. En un avance de lo que hasta el momento es su último libro publicado -en húngaro y en alemán ${ }^{1}$ - señalaba Kertész que lo suyo (habla en particular de Sin destino, pero otro tanto valdría de sus demás novelas) no es novela autobiográfica, esencialmente porque tal género no existe. Una cosa sería la autobiografía -explica-, de carácter documental; otra, la novela, en la que "lo importante no son los hechos, sino lo que se añade a los hechos" 2 . Se crea un mundo, un mundo soberano que nace en la cabeza del escritor y sigue las leyes de la literatura.

Aun cuando Kertész lo niegue -y con buena razón que aquí intentaremos elucidar-, en un sentido lato, aproximativo, puede decirse que toda su obra es autobiográfica: no sólo Sin destino, sino también Fiasco, que viene a recrear las circunstancias en que se escribió Sin destino; Kaddish, que indaga en el sentido que la escritura ha tenido en su existencia; La bandera inglesa, que es el relato del descubrimiento de su vocación de escritor; Liquidación, del fin del comunismo y las cuentas pendientes de Auschwitz. La única obra que, como él mismo dice, "se ha sacado de la manga", es la Historia de detectives. ¿Qué quiere decir aquí "autobiográfica"? Que su vida, que su "realidad vivida" es la materia prima de sus obras, nada más, y nada menos, porque eso confiere a sus novelas, no hay que olvidarlo, un punto de autenticidad difícilmente soslayable. Cuando uno lee Kaddish, al igual que cuando lee Sin destino, no puede dejar de pensar en el drama personal real y efectivo, como no se puede dejar de pensar en Auschwitz. Si se nos permite la paradoja, la realidad que sostiene el relato le confiere a éste un plus de verosimilitud; acaso no sólo un plus, sino hasta una diferente, más convincente, verosimilitud.

Con esto, insisto, no se pretende quitar validez alguna al rotundo aserto de que no hay género tal cual el de la novela autobiográfica. De hecho, en la versión definitiva del Dossier K. se repiten las mismas palabras ${ }^{3}$. Hay, sin embargo, algo que parece despojar de rigor lo anterior; y es que en una breve "advertencia previa" el autor nos asegura que este texto que tenemos ante nosotros, transcripción reescrita de largas horas de entrevista con un buen amigo suyo y lector, es una "autobiografía en toda regla”, aunque, eso sí -añade-, si hacemos caso a Nietzsche ${ }^{4}$, quien hacía derivar la novela de los diálogos platónicos, en ese caso, lo que el lector tiene en sus manos es "realmente una novela" (Kertész 2006: 5). ¿Con qué nos quedamos: son autobiografía y novela dos géneros inmiscibles o, por el contrario, según como se los mire, son indistinguibles el uno del otro?

\footnotetext{
${ }^{1}$ Cuando no hay traducción española, nos valemos de la alemana, al sernos inaccesible el húngaro original. La última obra publicada por el momento, finales de 2006, es Dossier K. Eine Ermittlung, aparecida en septiembre de 2006, de la cual se publicaron unas 45 páginas, de las 70 primeras del libro, en junio de 2005 (véase Kertész 2005b).

2 “[...] eine solche Gattung gibt es gar nicht. Entweder Autobiographie oder Roman. [...] Eine gute Autobiographie ist wie ein Dokument: ein Epochenbild, auf das man "sich stützen" kann. Im Roman dagegen sind nicht die Tatsachen das Entscheidende, sondern allein das, was man zu den Tatsachen hinzutut" (Kertész 2005b: 53.Traducción y cursiva, mía: J.A.).

3 Hay, sí, un cambio en la persona del verbo, que pasa del impersonal, man, a la segunda persona, $d u$, pero aquí carece de trascendencia (Véase Kertész 2006: 12).

${ }^{4}$ Kertész tradujo El nacimiento de la tragedia al húngaro. Allí encontramos lo que probablemente sea la referencia pertinente: "El diálogo platónico fue, por así decirlo, la barca en que se salvó la vieja poesía náufraga, junto con todos sus hijos: [...] Realmente Platón proporcionó a toda la posteridad el prototipo de una nueva forma de arte, el prototipo de la novela" (Nietzsche 1980: 121).
} 
Recordemos, "lo importante no son los hechos, sino lo que se añade". Estaríamos tentados de pensar que lo que se añade es lo imaginario, lo no fáctico, si acaso la forma, la estructura, digamos, narrativa, cierta necesidad fruto de la razón. Y no, diría que "lo que se añade" es el arte, es la escritura; es decir, no los elementos o los factores que componen el arte, sino el propio arte, la escritura. Por supuesto, entonces también la "autobiografía" sería escritura. Y, así, según como se mire, un texto puede ser a la vez autobiografía y novela; lo que nunca será -creo que en eso se reafirmaría Kertész- es «novela autobiográfica», género que no existe. ¿Por qué no existe?, o dicho de otro modo: ¿es posible mantener a la vez las dos proposiciones, la que parece distinguir tajantemente entre autobiografía y novela, y la que nos dice, en una suerte de juego borgeano, que el Dossier $K$. puede verse lo mismo como autobiografía que como novela? Nos parece que sí, mas sólo si entre una y otra se reconoce una intención diferente que acaba por sacar a la luz un cambio radical de presupuestos -llamémoslos- ontológicos.

En el primer caso, lo que se trata es de solventar el asunto de si lo que él escribe es «novela autobiográfica» o no. La novela autobiográfica, se sobreentiende, sería la mezcla de experiencia personal y ficción, el relato de experiencias propias del autor a las que se añadirían, mezclándolas sin distinción, «experiencias» imaginadas o ajenas. Cuando Kertész dice que tal cosa no existe, no está negando que se pueda construir un relato de tal manera; está indicando que ésa no es la cuestión: que un género no puede quedar definido por lo real o ficticio del origen de los materiales con que se construye el relato. Lo que nos quiere decir es que la supuesta mezcla de documento y escritura novelística hace que el documento deje de ser tal, no porque se le añada algo ficticio o imaginario, sino porque la escritura novelística transforma lo que toca: el documento vertido en novela pasa a ser novela. Lo que se añade no es nada, sino un diferente modo de ser.

Lo que primaba en la primera proposición era negar la posible existencia de algo así como la novela autobiográfica; y para ello distingue de manera en apariencia tajante autobiografía y novela. La intención de la primera proposición es absolutamente diferente de la segunda; y, así, la perspectiva. Lo que distinguiría autobiografía y novela es el modo de tratar los hechos entendidos en cuanto materia prima. En la proposición segunda la intención es bien diferente: no se trata ya de aclarar el asunto del supuesto género híbrido «novela autobiográfica», sino de especificar, yendo más allá de los hechos en cuanto materia prima, el nombre que corresponde al relato de la vida. Y en la ambigüedad del nombre, autobiografía y -si nos ponemos nietzscheanos- novela, se está destacando, de modo implícito pero ya insoslayable, una concepción de lo que sea la escritura que no se compadece con la manera tradicional de entender el lenguaje y su relación con la vida, con la existencia humana.

Parece, ésta es nuestra hipótesis, que lo que Kertész está, en el fondo, suponiendo es la imposibilidad de "reproducir" la vida, la existencia en un lenguaje "objetivo"; esto es, está de entrada negando que la autobiografía sea el documento, el informe, la versión objetiva de la existencia de alguien, respecto de la cual la novela entrañaría una desviación. Está negando que haya un "punto cero" de representación o mímesis de la realidad. Toda escritura, por el hecho de serlo, implica elaboración de un material, transformación y salto, paso de la existencia al lenguaje. El lenguaje, diríamos, no representa la existencia, sino que la interpreta, la expresa. 
Claro está, habrá que precisar lo que aquí signifique expresar, puesto que el sentido habitual que este término exhibe en las teorías de la expresión literarias se enmarca en última instancia en unos presupuestos -llamémoslos- ontológicos que no son los aquí aludidos. En el comienzo de su auge moderno, con el romanticismo, se entendía que la expresión lo era de sentimientos internos del poeta, mas no se dudaba de que dichos sentimientos poseían un modo de ser que no difería en el fondo de otros objetos para los que el lenguaje parecía, con todo, más apropiado. Había, sí, dificultad, falta de práctica, una riqueza subjetiva, pero nadie dudaba de que la relación entre lenguaje y sentimiento fuera la misma que la que se daba por supuesta entre lenguaje y realidad ${ }^{5}$. Desde entonces las cosas han cambiado, se ha pasado de un paradigma que podemos llamar representacional -que presupone homología entre obra literaria y experiencia vivida - a otro que se suele considerar hermenéutico, y que comportaría una radical "heterología" entre obra y vida. ¿Sigue siendo posible hablar de expresión cuando parece que la categoría básica que vincula experiencia y lenguaje es la de interpretación? O mejor: ¿qué significaría expresión cuando parece haber cambiado la relación entre lenguaje y experiencia?

Nos parece que tanto la indistinción sugerida por Kertész de autobiografía y novela como toda una serie de reflexiones y puntualizaciones, así como su praxis de la escritura, hallan su sentido sólo en el marco de ese paradigma que por comodidad llamamos hermenéutico. Nos referimos con él a esa época que se abre con la crítica de Nietzsche a la componente metafísica del lenguaje, que quedaría reflejada en aquel fragmento, desde entonces tan citado y maltratado, de "¡no hay hechos, sólo interpretaciones!"6.

En lo que sigue intentaremos esclarecer los presupuestos ontológicos de dicho paradigma, conocer los cuales nos parece imprescindible para tomar en serio la obra de Imre Kertész. En particular, cómo debe entenderse la relación entre la obra literaria y la vida del autor, y qué concepción del mundo, del lenguaje y del vínculo que entre ambos se da se hallan en la base de la anterior. Comenzaremos, entonces, por ver lo que Kertész nos ha dicho, ciertamente de manera rapsódica, nada sistemática, al respecto, e intentaremos luego ordenar y enmarcar dichas ideas en ese modo de ver el mundo que llamábamos hermenéutico por referencia a Nietzsche, Heidegger y -también-a Merleau-Ponty, con ayuda de los cuales leeremos a Kertész.

2. En una anotación de 1988, respondiendo implícitamente al tópico romántico aún en boga, dice Kertész: "Piensa mal del arte quien considera que transmite sentimientos. El arte transmite vivencia, la vivencia de vivir el mundo y sus consecuencias éticas." (Kertész 2004: 209. Cursiva, mía: J.A.) El arte transmite, sí, sentimientos, mas no sólo; lo que verdaderamente transmite es la vivencia de vivir el mundo, en la cual habrá sentimientos, es posible, casi seguro, pero no se puede reducir la vivencia

\footnotetext{
5 "La teoría expresiva de la creación poética, tan difundida en el período romántico, nos parece constituir todavía un avatar de la teoría imitativa, pues se reduce a transferir al dominio de la subjetividad lo que la teoría mimética afirma en el plano de la realidad objetiva. En efecto, la teoría expresiva tiende a concebir el poema como el término rigurosamente homólogo de la experiencia vivida" (Aguiar 2001: 111).

6 “Gegen den Positivismus, welcher bei dem Phänomen stehen bleibt ,es giebt nur Thatsachen“, würde ich sagen: nein, gerade Thatsachen giebt es nicht, nur Interpretationen" (Nietzsche 1988a: 315). Se ha publicado recientemente la versión española de dicho tomo y el siguiente: el "lema" nietzscheano se halla en el fr. 7 [60] (véase Nietzsche 2006: 222).
} 
al mero sentimiento y, en consecuencia, la función del arte a la transmisión de sentimientos ${ }^{7}$. Transmite, pues, una totalidad que es la vivencia, y entendida en cuanto acontecimiento en el mundo, $y$ del mundo, pues es la vivencia de vivir el mundo. El sentimiento se ha considerado tradicionalmente subjetivo, lo subjetivo por antonomasia. La vivencia podríamos entenderla también de ese modo, pero no: se subraya, a más del acontecer, la mundanidad ${ }^{8}$.

Es más, la anotación continúa: "El arte transmite existencia a la existencia. Para ser artistas, hemos de sustanciarnos en existencia, igual que el receptor, que también ha de sustanciarse en existencia. No vale conformarse con menos; y si algún significado posee este rito, únicamente se puede buscar aquî́" (Kertész 2004: 209. Cursiva, mía: J.A.)

No sólo, pues, que el arte transmita la vivencia a otros. No, es que el arte da vida a la vivencia, la recupera y la relanza, la arranca de sí para recrearla. Podría entenderse también que se refiere a la objetivación en la obra, mas parece que aquí no le es ajena la revivificación de la existencia. Al fin y al cabo, vivencia en sentido enfático suele decirse de aquellas experiencias inolvidables e irreemplazables, inagotables por lo que hace a su significación, para las cuales la creación artística, literaria sería ocasión de resurgimiento y plasmación en sentido. De hecho, años antes, ¿septiembre de 1983?, había anotado acerca de la verdadera función del novelista - un Proust, un Kafka, un Krúdy, no los que son unos chapuceros o unos charlatanes: "la novela: un proceso en cuyo curso uno recupera su vida", la rememora: ese "recuperar" sería, pues, "dar existencia a la existencia", revivir lo vivido $^{10}$.

Todas sus novelas tienen algo de eso. Sin destino, está claro, trata de formular, por decirlo así, la formación de un "sin-destino", de una "no-personalidad". No sabemos, ni probablemente él lo sepa, si el Kertész adolescente era o no como el György Köves de la novela. Pero hemos de suspender este presupuesto realista -el de que en la realidad vivida hubiera ya un significado que el escritor sólo tiene que notificarpara captar mejor lo que allí pasa; es una novela, no un documento.

\footnotetext{
7 "Nadie niega lo que, por otro lado, es evidente: que el autor se sirve de sus sentimientos, de su experiencia propia, para hacer la obra. Pero no se sirve exclusivamente de ellos: también cuentan (a veces más, según los casos) sus observaciones sobre lo que le rodea, sus creencias de toda índole, sus opiniones estéticas, la influencia de otras obras artísticas. Cuenta lo consciente y lo inconsciente, lo pensado tanto como lo vivido" (García Leal 2002: 200).

8 La caracterización que G. Simmel hizo del concepto de vivencia ayuda a precisar esto: "[en la vivencia] lo objetivo no sólo se vuelve imagen y representación como en el conocimiento, sino que se convierte por sí mismo en momento del proceso vital” (cit. en Gadamer 1996: 106).

9 "La inestimable importancia de la novela: un proceso en cuyo curso uno recupera su vida. [...] el único objeto posible de la novela: la recuperación, la vivencia de la vida, y que nos colme por un solo y fervoroso instante antes de partir" (Kertész 2004: 148).

10 Aun cuando estemos, por economía, valiéndonos del término que Dilthey y Husserl introdujeran en el pensamiento filosófico, probablemente sea más cercano al uso que le estamos dando lo que Merleau-Ponty llamaba Erfahrung, y que contraponía expresamente a la Erlebnis husserliana. Esta sería "experiencia articulada, voluntaria y consciente cuyo recuerdo puede ser evocado a voluntad", y la señalada Erfahrung, "experiencia silenciosa, originaria y crepuscular que nuestro cuerpo mantiene con el mundo sensible y cuyo recuerdo sólo emerge por una causa involuntaria y contingente" (Bech 2005: 108-109). Vivencia, tal como empleamos aquí el término, es la experiencia que ha sido vivida real y efectivamente, con independencia de que haya llegado o no a ser consciente.
} 
En una primera lectura suele llamar la atención lo que a veces se llama la "objetividad" de la narración. No es término nada afortunado, pero sí una advertencia que conviene indagar. Por otro lado, no hay que olvidar que la obra, en un primer momento, llegó a escandalizar. La razón más clara de esto es que, como señala en el último capítulo el propio protagonista, no se ve que el campo de concentración, Auschwitz, digamos, sea el infierno (Kertész 2001a: 248-9), y eso choca y hasta produce indignación en las buenas conciencias, que de pronto se ven enfrentadas a la duda de si, como habían llegado a convencerse, será que Auschwitz no fue tan malo. Obviamente se leía el texto como mera representación del campo de exterminio.

¿A qué se refiere esa mal llamada objetividad? Al hecho, diríamos, de que el protagonista y narrador -como en sus términos nos advierte Kertész- actúa como sensorio del mundo: lo que él va exponiendo es la memoria recreada de la experiencia, llamémosla, estética, sensorial -lo que va viendo, lo que va sintiendo, lo que va pensando. Y esa experiencia estética, hay que recordarlo, es lo más primario en la vida humana, diríamos que es previa al sujeto entendido en sentido estricto. Ciertamente, el protagonista convertido en sensorio puro no es un carácter, no es un personaje, ni es un individuo. No podemos hablar de objetividad en sentido estricto porque la narración está llena de sentimientos, sensaciones, juicios estéticos, a más de intentos continuos de explicación racional de los acontecimientos. Lo que no hay -iy eso es lo que lleva a hablar imprecisamente de «objetividad»!- es sentimentalidad ni juicios morales condenatorios.

En el primer capítulo prima el desconcierto o, mejor, lo que podríamos considerar inmadurez: el niño, que hoy no ha ido a la escuela -comienza así la novela-, no entiende muy bien, no entiende nada. Y, sin embargo, a través de él -la narración es en primera persona- el lector ve lo que pasa.

En el segundo capítulo hay una escena especialmente llamativa, reveladora de la inconsistencia del adolescente, pero también de esa configuración presubjetiva del personaje. Discutiendo con una vecina de su edad acerca de ese "ser judío" que los está marcando, ante la desesperación de la niña, piensa en decirle que él no la desprecia por ser judía; no obstante, se calla, lo que a la vez le molesta. En esa compleja tesitura siente por primera vez "algo que quizá podría llamarse vergüenza" (Kertész 2001a: 47). El ha sido en cierto modo el culpable de que la vecina capte la casualidad de todo, el sinsentido. Y, sin embargo, el adolescente, que narra en primera persona, aparece no tanto como el actor, sino como el espacio en que un zigzag de ideas y afectos se entrecruzan y deciden su actuación: "Estuve en un tris de decirle... Menos mal que enseguida caí en la cuenta... Sin embargo, me molestaba... Aunque es posible que en otra situación... No lo sé. También reconocí que...” (Kertész 2001a: 47).

Dos cosas llaman especialmente la atención:

a) las apreciaciones estéticas (dicho ahora en el sentido más estrecho del término), admirativas por lo general de los verdugos: al llegar a Auschwitz el arreglo y la vestimenta de los soldados alemanes le tranquiliza; ante el médico que selecciona a los que van a vivir, y envía a los demás a las cámaras de gas, siente «confianza, puesto que tenía buen aspecto y una cara simpática»; antes de las duchas han de entregar todo lo que lleven encima a un «preso muy elegante», que le ayuda, y a un soldado bajito, etc., que, sin embargo, es propietario de «un látigo de cuero blanco 
- una verdadera pieza de artesanía, tuve que reconocer» (Kertész 2001a: 84, 90, 95). Basten estas referencias ${ }^{11}$.

Tales apreciaciones estéticas sacan obviamente a la luz la formación del gusto del narrador, y ese gusto condiciona o está inextricablemente unido a toda una serie de prejuicios de índole también moral. Lo que escandaliza, entonces, al lector desprevenido, el de la buena conciencia, es que la moral que aquí sale a relucir sea justamente la que, si no dio origen, desde luego, sostuvo el nazismo ${ }^{12}$. El narrador no sólo desconfía de las caras de los presos, a su llegada a Auschwitz, presos que, además de ser-por definición- criminales, le resultan sospechosos y ¡le parecen judíos!, sino que una vez seleccionado, comprende el trabajo del médico y mira con sus ojos: «Al mirarlos con los ojos del médico, me di cuenta de cuántos viejos e inútiles había» (Kertész 2001a: 82, 92). Y en esta reflexión tenemos:

b) la entrega del adolescente a la racionalidad imperante, o una búsqueda desproporcionada - para el lector- de racionalidad, de armonía y orden. "Comprendí las razones de su animadversión hacia los judíos"; "comprensible" -también- que en el tren se muera la vieja; "tan elegantes" los soldados... que tranquilizan; "todo era pulcro, cuidado y hermoso", bien que "no había ninguna señal de vida" (Kertész 2001a: 16, $79,84,94)$, etc. Por supuesto, dicha entrega es respuesta a la extrañeza, la ignorancia, la falta de elementos de juicio, el sinsentido, en definitiva, del mundo totalitario. Hay un esfuerzo intenso, por más que inconsciente, por mantener los límites que distinguen y separan orden y caos, reprimiendo incluso la sensación de extrañeza a favor de una supuesta armonía. Al final del capítulo cuarto -el de la llegada a Auschwitz- dicho esfuerzo, sin embargo, resulta ya baldío: "No sé bien qué ocurrió [...] y no supe siquiera dónde estaba" (Kertész 2001a: 103)... han llegado los primeros golpes.

Por cierto, es esa convivencia chocante entre la pretensión de racionalidad absoluta y la verdad de la experiencia lo que caracteriza la ironía demoledora del texto: efecto del desajuste entre lo que sabemos de Auschwitz y el intento de racionalización de lo que allí sucede. Kertész se apoya en lo que el lector sabe de los campos de concentración alemanes; sólo así puede entenderse el carácter provocativo de la narración. Lo que ésta expone a la luz es el fruto de la educación recibida por el narrador adolescente, y en el mundo así configurado los alemanes tienen razón; es más, son la razón. El campo quizá no sea lo natural en este mundo, mas una vez que se está en el campo, el campo pasa a ser lo natural, y todo lo que en él sucede es racional, esto es, puede ser explicado mediante razones. Así que, por otro lado, y esta doblez de la ironía es esencial, el campo es lo más natural. Acaso sea ésta la idea central que nos transmite Sin destino. El escándalo, decía, cala en la buena conciencia, es decir, en quien no ha pasado por Auschwitz. Pero es que Auschwitz, efectivamente, es inimaginable. Por eso, Kertész no pretende darnos una imagen de ello, no trata de representárnoslo. Si lo tomamos como representación del campo es cuando Sin destino escandaliza, porque en la representación sancionada de Auschwitz está incluido el juicio condenatorio,

\footnotetext{
11 Véanse también, sin pretender ser exhaustivo, Kertész 2001a: 119, 138, 181, 192, 194, 202.

12 En diversos lugares insistirá Kertész en que Auschwitz no es una excepción, no es un corte en la historia de occidente. En Kaddish..., por ej.: "Auschwitz, dije a mi mujer, me pareció más tarde una mera exacerbación de las mismas virtudes para las cuales me educaron desde la infancia” (Kertész 2001b: 137). Puede verse también Kertész 2002b: 33, 80.
} 
o la figuración del horror. No, eso es lo que Kertész no hace. Kertész nos presenta los argumentos de Auschwitz, a través de un perceptor, por decirlo así, universal. Y, ¡cuidado!, ya lo hemos visto, la percepción no es subjetiva: es fruto de una educación estética y moral, e intelectual. El narrador no trata de presentar su peculiaridad, su individualidad sino que a través de él surge a la palabra el mundo en que se ve inmerso. Y ese es un mundo en que la persona, la personalidad han desaparecido, están de principio excluidas. El conjunto de determinaciones de dicho mundo ocupa el lugar de lo que sería la historia personal de cada uno. A esa determinación exterior, caprichosa, absurda, basada en la vaciedad de la ideología nazi, es a lo que Kertész llama "sin destino", por más que se imponga con la férrea necesidad del verdadero destino. Bien que éste sólo puede desplegarse en compañía de la libertad. En cualquier caso, ese "sin destino" será algo que el adolescente deberá asumir como destino propio: uno no puede olvidar que ha pasado por Auschwitz. Y, aun cuando lo hiciera, Auschwitz nunca dejaría de ser la gran huella, el agujero irrellenable del trauma y, en el caso concreto de Kertész, a la vez el acicate y el motivo de la escritura.

En fin, si Auschwitz no se puede representar es porque hay una diferencia radical entre lo que se vive y lo que se habla de lo que se vive, y cuando no se ha vivido Auschwitz, nada se puede entender a partir de la representación. "El campo de concentración sólo puede imaginarse como texto literario, no como realidad" -y añade entre paréntesis- "(Ni siquiera cuando lo experimentamos; quizá sea entonces cuando menos lo experimentamos como realidad.)” (Kertész 2004: 222. Cursiva, mía: J. A.) De ahí que Kertész trate de exponernos no la imagen, sino la "lógica" de Auschwitz. Ahora bien, si hemos de tomar en serio la advertencia, esto implica una concepción del lenguaje que, como ya apuntábamos, no es la representacional; una relación entre lenguaje y vida que habrá que aclarar.

Dejo aquí Sin destino. Sabemos que se salva por la acción de algunos personajes que todavía conservan capacidad de decisión libre y ética. Pero antes el adolescente se ha abandonado, se ha entregado a la muerte. La novela configura el in crescendo del sentimiento de extravío en el mundo arbitrario del campo. La novela no nos relata el camino de formación de un personaje, sino la vía de disipación y perdición que lleva desde el no saber y el no entender hasta la casual supervivencia en la soledad, pasando por el abandono y la renuncia. El adolescente protagonista, como explica el propio Kertész: "solamente consiste en determinaciones, reflexiones y tropismos: solamente lo hace hablar, siempre y en todas partes, la tortura a la que lo somete el mundo, de lo contrario ni siquiera sabría usar la palabra; él nunca hace hablar al mundo" (Kertész 2004: 31).

Vista, siquiera sea en esbozo, el alma de Sin destino, palidece lo autobiográfico. Kertész se pasó ¡catorce o quince años! escribiendo la novela. Lo que le movía era apurar y elaborar aquella vivencia básica que le perseguía. No se puede rendir cuentas de un "sin destino" mediante caracteres ni personalidad. Por eso debía prescindir de lo autobiográfico, porque se trataba de proponer una "im-personalidad"13.

Esa es una manera de recuperar la vida, de dar existencia a la existencia. Otras novelas reflejan otros modos. En definitiva, es siempre la vida, el deseo de vivir lo

\footnotetext{
13 "Sin destino como novela autobiográfica. Lo más autobiográfico de mi autobiografía es que no hay nada autobiográfico en Sin destino. Lo autobiográfico de ella es que eliminé todo lo autobiográfico en aras de una fidelidad superior" (Kertész 2004: 164).
} 
que hace a la obra de arte ${ }^{14}$. De ahí que para Kertész la escritura sea una venganza que se toma con el mundo, ese mundo -totalitario ya "antes de" Auschwitz-, cuya esencia es negarle en cuanto individuo ${ }^{15}$. Una venganza, una respuesta y una manera de apoderarse de la realidad.

Apoderarse de la realidad, vengarse no son tareas estériles. Son parte de una operación que actúa sobre el propio autor. La escritura le sirve para vivir, para soportar su existencia, y justificarla, pues con la escritura la va transformando. En más de un lugar viene a decirnos que la escritura es un modo de disimular, de olvidarse de sí mismo. Mas esa huida tiene su lado positivo: se trata de dejar atrás ese "sí mismo" que es el fruto de determinaciones externas, "náufrago del azar, siervo de la electrónica biológica, hombre asombrado, muy a su pesar, de su propio carácter" (Kertész 2003: 59).

El último capítulo de Fiasco, que es una conclusión en que la cosa no acaba, "puesto que, como bien sabemos, nunca nada acaba", nos da Kertész una versión feliz - ¿inspirada en la de Unamuno?- del mito de Sísifo, en que el escritor escribe y escribe, liberándose de lo superfluo, la vida. Dejar atrás aquel "sí mismo sin destino", liberarse de él, hasta el punto de que al ponerse a escribir le desaparezcan los recuerdos ${ }^{16}$, va a ser la función de la escritura. "Lo que se añade a los hechos" es nueva vida, es otra vida.

Tenemos ya una primera respuesta a la cuestión acerca de la relación entre la vida del autor - ¿la autobiografía?- y la novela: la novela es una transformación de la existencia del autor, entendida ésta en cuanto materia prima para la elaboración de aquélla. La novela, el arte en general tienen por función rescatar algo de la vida, aunque no sea más que el deseo; mas no tanto porque se apoyen en ella, sino, más bien, porque la recrean. Y esto, la recreación, el logro de la transformación y, con ello, de una nueva vida, no se mide en absoluto por el grado de realismo ni de correspondencia con los hechos efectivos de la vida del autor, que acaban por molestar. La clave parece estar, entonces, en el hecho de que no sólo el arte necesita de la vida, sino también, a su vez, la vida necesita del arte.

\footnotetext{
${ }^{14}$ A más de ser, junto con el humor, uno de los rasgos característicos de sus novelas, lo señala explícitamente en diversos lugares (véase, por ej., Kertész 2004: 11-12, 22, 176). En Sin destino una de las escenas más singulares, motivo también de escándalo, es la que funde deseo de vivir y belleza ¡del campo de concentración!: "En mi interior identifiqué un ligero deseo que acepté con vergüenza -porque aun siendo absurdo, era muy persistente-, el deseo de seguir viviendo, por otro ratito más, en este campo de concentración tan hermoso" (Kertész 2001a: 192).

15 “...] tal vez empecé a escribir para vengarme del mundo. Para vengarme y arrancarle aquello de lo que me excluyó. [...] Tal vez quería eso, sí: sólo en la imaginación y con instrumentos artísticos, apoderarme de la realidad que -de forma muy real- me tiene en su poder; quería convertir en sujeto mi eterno ser-objeto, ser dador de nombres en vez de nombrado. Mi novela no es más que una respuesta al mundo: el único modo posible de respuesta que me quedaba" (Kertész, 2003: 95 Cursiva, mía: J. A.). Fiasco es un ejemplo perfecto de esa venganza: en lo que tiene de parodia de un lenguaje objetivo, barrenado por continuas explicaciones desternillantes... Pero, sobre todo, en ese velo de inconsistencia, de fragilidad y ruina que arroja sobre un mundo en que se reconoce a distancia el comunista, llegando a producir hasta piedad: ¡el mundo comunista!

16 "[los recuerdos...] se convirtieron en otra cosa. Se transformaron en contenidos de diversos cajones, donde rebuscaba cuando lo creía necesario para extraer alguna moneda convertible. Los elegía: necesitaba este y no aquel. Los hechos de mi vida, la llamada "materia de mi experiencia", ya sólo molestaban, dificultaban y limitaban mi trabajo, la creación de la novela a la que, en un principio, servían de base existencial" (Kertész 2003: 78).
} 
3. Y es que el arte, la creatividad, son una función vital. Contra los tópicos románticos del genio, el talento, etc., "la creatividad -dice Kertész- no es un don divino venido de fuera, sino una función vital, el instrumento necesario para quedar con vida" (Kertész 2004: 174). Una función vital que se puede atrofiar, que en la mayor parte de los casos está atrofiada. En el suyo, sin embargo, se ha convertido en necesidad. Por haber descubierto en él precisamente esa posibilidad de ir alimentado la existencia, de ir transformándola en algo real, de objetivarla en obra ${ }^{17}$. El último fragmento del Diario de la galera contiene un sueño, una fantasía de un músico feliz que lleva décadas tocando variaciones sobre un mismo tema y va ya por la enésima -en los ratos libres que le deja el trajín de la vida cotidiana-. En esa música, imagina Kertész, se reconoce "la obsesiva voluntad expresiva" (Kertész 2004: 277). La existencia, diríamos entonces, posee una voluntad de expresión que, hecha obsesión, necesidad, redunda en la creación artística.

El encuentro con esa función vital, el descubrimiento de esa voluntad de expresión nos lo narra Kertész en La bandera inglesa; es lo que él llama el momento de la radicalización de su vida. El la cifra en su encuentro con la ópera wagneriana $L a$ Valquiria y el relato de Th. Mann "Sangre de Welsungos", inspirado a su vez en La Valquiria. Los personajes del relato son también Siegmund y Sieglinde, en este caso dos jóvenes aristócratas berlineses dados a la molicie. Atendiendo a la representación de la obra wagneriana se refleja ésta en los rostros de ambos. Piensa Siegmund:

\begin{abstract}
¡Una obra! ¿Cómo se hacía una obra? Se formó un dolor en el pecho de Siegmund, un ardor o una tirantez, algo parecido a un dulce apremio. Pero un apremio ¿hacia dónde? ¿Por qué? Todo resultaba tan oscuro, tan ultrajantemente confuso. Estaba sintiendo dos palabras: creatividad..., pasión... Y mientras el acaloramiento le latía en las sienes, tuvo la nostálgica idea de que la creatividad procedía de la pasión, cuya forma volvía a adoptar de nuevo tras haber creado. Vio a aquella mujer blanca y fatigada rendida sobre el regazo del fugitivo al que se había entregado, vio su amor y su necesidad y sintió que la vida, para ser creativa, tenía que ser así. Contempló su propia vida, esa vida compuesta de blandura y de ingenio, de mimos y de negación, de lujo y de contradicción, de suntuosidad y de claridad racional, de rica seguridad y de un odio travieso, esa vida en la que no había vivencias, sino sólo juegos de la lógica, ni sentimientos, sino sólo una aniquiladora precisión... Y en su pecho latía un ardor o una tirantez, algo parecido a un dulce apremio. Pero un apremio ¿hacia dónde? ¿Por qué? ¿Por la obra? ¿Por la vivencia? ¿Por la pasión? (Mann 2001: 367. Cursiva, mía: J.A. ${ }^{18}$ )
\end{abstract}

\footnotetext{
17 Ya Nietzsche insistió en considerar la creación artística como "esencia" de lo humano. En numerosas ocasiones -como apunta Heidegger (1989: 135) - con "creación" se refería Nietzsche al carácter inventivo de la vida sin más, pero en sus últimas obras entiende la creación como Kertész la va a tratar: será la obra lo que dé sentido a la existencia del autor. Se reunirían así los dos aspectos: la creación en cuanto ejercicio vital y en cuanto producción de obra. Es más, Nietzsche nos propone una visión del artista por relación a la obra asimismo muy cercana a la de nuestro escritor: "En última instancia él es tan sólo la condición preliminar de su obra, el seno materno, el terreno, a veces el abono y el estiércol sobre el cual y del cual crece aquélla" (Nietzsche 1975: 117).

18 En negrita lo que Kertész cita en 2005a: 41.
} 
En el relato de Th. Mann parece que el apremio les lleva a la pasión incestuosa. A Kertész le dio por la obra, por la escritura. Radicalizar, entonces, su vida es literalmente hacerse cargo de la pasión, raíz de la existencia, y recrearla en obra. El ya escribía, había sido periodista y tenía su sueño de escritor. Lo que la radicalización va a suponer es que la formulación, la narración de su existencia no se contradiga con la propia existencia, con su forma de vida. Que no se contradiga quiere decir que de algún modo se adecue la experiencia al papel, sin que eso signifique que entre la existencia y su formulación deje de haber un "telón de acero" -dirá él-, telón de acero que separa al hombre de sí mismo. Acaso en vez de "telón de acero" debiéramos decir una diferencia, digamos, de "sustancia", pues una cosa es la vida y otra, la narración y su medio, el lenguaje, por más que el lenguaje forme parte de la vida. Sin embargo, Kertész ve en el lenguaje -en el lenguaje hablado- una tendencia a velar el $\operatorname{ser}^{19}$. Al menos, en el lenguaje dado. De hecho, entiende que lo que hace a un hombre escritor es justamente ese no aceptar el lenguaje y los conceptos dados. Hay, pues, un telón de acero, incluso cierta oposición en tanto no se reconozca dicho telón, entre lenguaje dado y existencia; tanto más cuanto que la existencia radical debe ser individual y el lenguaje dado es institución social, es palabra ya hablada, y, así, desarraigada. La radicalización, dicha en otros términos, vendría a suponer que se da una forma adecuada a esa voluntad de expresión, que se la convierte en significación, en sentido, a través del trabajo y la apropiación del lenguaje.

La atención a la pasión, la dedicación a la creación permite descubrir la vida, algo otro en uno mismo. De los Carnets de Camus cita Kertész una frase de Van Gogh: "Puedo prescindir perfectamente de Dios en la vida y en la pintura, pero enfermo y todo no puedo prescindir de algo que es más grande que yo, que es mi vida: el poder de crear" (Kertész 2004: 131. Septiembre de 1982. Cursiva, mía: J.A.). Nueve años después es él mismo el que viene a señalar esa experiencia de cierta otredad en la creación, aun cuando sólo sea de una simple ocurrencia, y es que no sabemos de dónde sale: "No sé quién escribe dentro de mí, quién es el escritor. Y está bien que así sea" (Kertész 2004: 264).

Por otro lado, su Yo, otro. Crónica del cambio, siendo anotaciones extraídas de su diario de entre los años 1991 y 1995, está dedicado en su totalidad a la cuestión del otro en uno mismo. Baste uno de los epígrafes, el propio de Kertész, para que se vea por dónde van los tiros: "“Yo": una ficción de la que a lo sumo somos coautores" (Kertész 2002a: 5) ${ }^{20}$. Y eso que se llama "otro" es lo que otras veces, al carecer de nombre propio, se llama "la vida", respecto de la cual entiende Kertész:

\footnotetext{
19 “QQué es el lenguaje? ¿Vela o desvela? Quizá más bien lo primero: vela el ser, a1 que interpreta como algo muy distinto, como lo radicalmente otro. Lo normal es el ser que da la espalda a la existencia; pues quien mira su interior o bien enmudece o bien "enloquece"" (Kertész, 2004: 239). Está pensando, ciertamente, en el lenguaje instituido, ya hecho, el que Merleau-Ponty denominará "palabra hablada", por oposición a la auténtica o "hablante", que habría que considerar, dice, "como un velo alzado" (Merleau-Ponty 1970: 243). Así, el escritor sería aquel que no entiende bien las palabras, y por eso se pone a escribir, como para curarse de una enfermedad: "quizá no sea sino el hecho de no aceptar el lenguaje y los conceptos dados" lo que hace a un hombre escritor (Kertész 2004: 19-20).

${ }^{20}$ Una vez más, la idea de Nietzsche de que el sujeto no es sino una pluralidad de voluntades de poder, una multiplicidad que se ha construido una unidad imaginaria nos ayuda a entender lo que Kertész dice. Como explica D. Sánchez Meca: "todo individuo guarda en su interior más personas, más máscaras de las que él mismo se cree. Se familiariza generalmente con un rol en función de su sexo, edad, etc., incorporándose
} 
Sería un error suponer que mi vida es mía. Pero un error todavía más grande sería abandonarla, estropearla, echarla a perder. Esta vida me ha sido confiada. No pregunto por quién, puesto que conozco la respuesta y sé, por tanto, que la pregunta está mal planteada; sólo puedo fiarme de mi propia e indiscutible percepción de la responsabilidad. Mantengo una relación de reciprocidad con mi vida. ¿El nombre de esta relación? Servidumbre. Hasta aquí todo bien. Pero, ¿qué partícula de esta vida fragmentada se refiere a sí misma con la palabra "yo"? (Kertész 2002a: 12-13).

Tan es así que hasta podría considerarse Yo, otro una novela, la novela en que se expone la fragmentación característica que introducen la reflexión y el tiempo en el supuesto continuo y la totalidad de esa vida que es raíz, es otredad y relación de reciprocidad con uno mismo. De hecho, en esos primeros años noventa, por lo que se ve en el texto, Kertész no para de viajar, se ha convertido en escritor conocido y reclamado. Yo, otro -resumiendo- sería la crónica de sus viajes por los lagos de Austria y Suiza... y también del alma.

El dicho de Rimbaud, "yo es otro", o acaso mejor el de Nerval, "yo soy el otro", nos acercan a Kertész, quien probablemente diría: "yo he de ser mi otro", el que me empuja a escribir, la pasión que me configura, moviéndome y removiéndome de donde estoy, de lo que soy. Esa diferencia en sí mismo, esa alteridad es la que marcaba antes el "telón de acero" que nos divide a cada hombre y, por supuesto, al hombre y al mundo, aunque sólo sea por la mediación del lenguaje. La negación de la novela autobiográfica era también una advertencia acerca de la imposibilidad de reproducción lingüística de la realidad: "Conversación. Mi interlocutor cree que lo extraordinario del mundo se puede reducir y convertir en algo formulable. Ser artista significa precisamente lo contrario" (Kertész 2004:144-145). Es decir, "ser artista” significa no creer que lo extraordinario del mundo se pueda reducir y convertir en algo formulable. El mundo, el ser sobrepasan lo formulable; y, a la vez, la acción del artista implica que, si no formular -o reducir a fórmula-, se puede expresar, articular.

La vida, el mundo, probablemente no se puedan entender. Heredero en ese aspecto del pensamiento de Camus, Kertész lo proclama de muy diversas maneras. La narración, sin embargo, el relato existencial que él practica no pretende apoderarse de su existencia, sino, lo veíamos, darle juego, devolverle la vida: en la obra. ¿Cómo hacerle hablar? Sólo en cuanto realidad narrable, dirá (véase Kertész 2002a: 109-112). Y esa realidad narrable sería "su contenido oculto, los resortes del teatro de marionetas". Supuesto que eso se logra, "el relato narraría la lucha sin fin que se inició en mí de forma imperceptible, como los cambios que se producen en un germen, para que ascendiera de las profundidades insondables de la existencia a la superficie de la conciencia, y para que luego aceptara la existencia (mi existencia) con esta nueva conciencia" (Kertész 2002a: 110).

Esa diferencia implica que "el fracaso está de entrada garantizado": la escritura copia la vida como si ella, la escritura, fuese vida, pero ¡no lo es!, reflexiona Kertész en un momento en que ¡sus propias historias le aburren! ${ }^{21}$ Algo, no obstante, hay de

juicios, opiniones, gustos, maneras de actuar, que cuadran con él. No obstante, si la vida lo requiere, cambia de rol" (Sánchez Meca 1989: 164).

21 «[...] vivo y escribo, y ambas cosas suponen esfuerzo, la vida es un esfuerzo más bien ciego y la escritura, un esfuerzo más bien vidente que se distingue por tanto de la vida, claro, y que tal vez se esfuerza por ver aquello por lo que se esfuerza la vida y, como no puede hacer otra cosa, repite la vida de la vida, copia la 
cierto en ello: la escritura implica, alberga un fracaso, una quiebra, una alteración de la vida, bien que dicho fracaso constituye una nueva vivencia, probablemente una fundamental, radical. La asunción de tal fracaso, el salto de la vida a la escritura es lo que permite que la obra de arte se dé sus propias leyes. Esto no ha de hacernos olvidar que ni la propia vida es como la vida, no reproduzcamos el dualismo clásico que entiende vida/lenguaje en cuanto oposición, no volvamos al tópico decimonónico que excluye del arte la vida. Que el mundo no es comprensible o reducible a fórmulas, que la vida no está hecha para entenderla, sino para vivirla significan justamente eso: el telón de acero, la diferencia constitutiva no separan sólo lenguaje y vida sino que habitan la propia vida entendida en cuanto raíz y existencia, esto es, en su totalidad. Sólo que esa separación no es necesariamente oposición y exclusión. Aun en la diferencia existe la posibilidad de una expresión lograda: tal es el texto del escritor.

Trabajar en la escritura viene a ser, por lo tanto, para Kertész una manera de trabajar en uno mismo, de conocerse a sí mismo, como diría Schopenhauer, una de sus lecturas favoritas. Ser para conocerse, escribir para ser, para conocerse. Sólo que trabajar en uno mismo es al tiempo trabajar contra sí mismo; al menos eso es lo que Kertész ve en Kafka y lo que considera propio de todo verdadero artista (véase Kertész 2004: 37). Si la pluralidad que albergamos en nosotros no queda a veces tan clara, lo que resulta innegable es que somos por lo menos dos: 1) el de antes, el que ha sido hasta ahora, y 2) el que ahora está siendo, y que puede ser otro. Tal es la forma más simple de la libertad humana; practicarla implica ir "contra" sí mismo, aun cuando sea para tomar apoyo.

En la objetivación que la obra de arte supone "el artista se ve a sí mismo como una necesidad sustancial, como la esencia destilada del momento histórico universal" (Kertész 2004: 37-38). Está hablando de Kafka, de las "K" que aparecen en El castillo y El proceso, "que al plasmarse no contienen nada personal, sino sólo lo general, convertido en algo extraño y, al mismo tiempo, válido". Esa destilación de lo personal en universal y válido es la objetivación de la obra lograda. Se ha dicho, y con razón, que la obra de arte ejemplifica, singularizándolo, lo universal; y eso es lo propio de la expresión frente a la representación.

Desde esta perspectiva habría que leer todas sus obras, las de Kertész. De ahí que tenga sentido su protesta frente al rótulo de "novela autobiográfica" que se aplicó a Sin destino, y que igualmente valdría de las demás. El habla de una noche de tormenta, en mayo de 1976, en torno a la cual gira la experiencia central de Kaddish, tormenta en la que habría entrevisto todas sus obras. Ciertamente, al menos Fiasco y Kaddish pueden considerarse hijas de aquella noche. La noche mentada anotaba en su diario:

Coñac, tranquilizantes. Gran tormenta en el exterior. A lo lejos, el espejo del agua que de vez en cuando se ilumina con colores rojizos. Y por fin la sensación del retorno, por fin la liberación, por fin el plan: LA GÉNESIS... sinfonía de una novela no nacida (como subtítulo). Quiero hablar, confesar, contar la historia de la liberación de un alma o, mejor dicho, la historia de una gracia (Kertész 2004: 62).

vida como si ella, la escritura, fuese vida, y no lo es, no lo es de una manera fundamental, incomparable, de una manera, incluso, que no tiene parangón, de tal modo que, cuando nos ponemos a escribir, a escribir sobre la vida, el fracaso está de entrada garantizado» (Kertész 2001b: 58-59). 
La génesis... acabaría siendo Fiasco. Surge el plan de la novela como reposo tras la lucha, como liberación. De ella, releyendo anotaciones de ese año 1976, dirá más adelante, en octubre de 1987: "Fiasco creció en mí, se desarrolló en mí y se separó de mí como el fruto de una planta" (Kertész 2004: 203). Algo parecido nos viene a decir la "tesis" que articula Kaddish: la escritura como oración fúnebre y testimonio de los hijos no habidos. Pero frente al aspecto en apariencia negativo de esta última idea, hay que detenerse en la, si se quiere, ingenua y poética imagen de la novela como fruto de la existencia humana. Recordemos la amplificación nietzscheana: el artista visto como el terreno, a veces el abono y el estiércol sobre el cual y del cual crece la obra. La obra es obra por crear su propia posibilidad. De esa manera se diferencia la vida de sí misma. Y en Fiasco podemos verlo aún mejor: por contener la obra el propio camino hacia la obra, y cerrarse al final en un bucle abierto. Recordemos: la primera parte es el documento de la posibilitación de la obra que la segunda parte va a ser; hay una conclusión no concluyente en que se remite a la piedra desgastada de un Sísifo feliz.

Los finales de Fiasco, Kaddish y Liquidación tienen ese rasgo en común: ser bucles abiertos, puntadas en proceso, como el vínculo de escritura y vida, como la temporalidad y el lenguaje. La escritura, entonces, no es sólo fracaso: es vida potenciada, vida intensamente vivida, el recto camino hacia la muerte. ${ }^{22} \mathrm{El}$ gran enemigo no es la muerte allá, sino la muerte en vida, el abandono, "la distracción existencial", que dirá Kertész ¿siguiendo a Pascal? (Kertész 2002a: 104). Eso es lo que hace de la vida mera supervivencia, lo que la despoja de su creatividad.

La creación, pues, es el modo de vivir, el modo de escapar a la condena del totalitarismo y de Auschwitz, el modo de llegar a ser individuo arrancándose a la Historia, de mantener viva la vida y cumplirla como camino hacia la muerte. Si, además, en el proceso algo se llega a conocer, tanto mejor; mas no es ese el fin primero de la creación artística. Se puede entender ahora mejor en qué sentido la escritura es para Kertész soporte y hasta justificación de la existencia. No sólo aparta del escritor lo terrible de la existencia; es que incluso lo redime y lo transforma en alegría, nos dice en el último texto hasta ahora publicado ${ }^{23}$. Retomando la idea de Th. Mann, continúa: "sólo se puede escribir cuando hay energía en abundancia, esto es, a partir del deseo; la escritura -y esto no me lo he inventado yo- es vida potenciada"24.

4. Señalemos de manera sumaria lo que hemos encontrado en Kertész acerca de la creación literaria:

\footnotetext{
22 Tal es el motivo de Kaddish, y una de las caracterizaciones que Platón hacía del pensamiento. No hay aquí espacio para rastrear el hilo que une a Platón con Th. Mann -La muerte en Venecia- y Kertész, en principio bien fecundo.

23 " [...] und von dem Moment an, in dem ich mich fürs Schreiben entschieden hatte, konnte ich meine Probleme auf einmal als Rohmaterial für meine Kunst betrachten. Und wenn dieses Material auch ziemlich düster zu sein scheint, wird es doch durch die Form erlöst und damit in Freude für mich verwandelt" (Kertész 2006: 67). [“...y desde el momento en que opté por la escritura pude de golpe considerar mis problemas como materia prima de mi arte. Y aun cuando esa materia parezca ser un tanto tétrica, por medio de la forma, sin embargo, queda redimida y se transforma para mí en alegría”. Traducción, mía: J. A.]

24 "Schreiben kann man nur aus der Fülle der Energien, also aus Lust; Schreiben, das habe nicht ich herausgefunden, ist gesteigertes Leben" (Kertész, 2006: 62. Cursiva, mía: J.A.).
} 
1. Una suerte de coimplicación entre arte y vida: la vida se expresa en el arte y el arte potencia la vida del autor, transformándola.

2. Dicha transformación es posible porque el arte es una función vital, porque la vida es voluntad de expresión.

3. La transformación se da por medio de una radicalización de la existencia, que es atención y cuidado de la pasión que la mueve.

4. Tal radicalización supone el descubrimiento de cierta otredad en uno, y es gracias al diálogo con eso otro como se transforma la existencia del escritor.

Quedarían por aclarar mejor -para que se entienda en qué sentido la obra es expresión de la existencia- un par de cuestiones:

a) que no se trata de expresión meramente subjetiva, esto es, de los sentimientos o intimidad psicológica del autor;

b) cómo es posible que habiendo un "telón de acero", una diferencia substancial entre vida y lenguaje, aquello que se hace con lenguaje, como es la narración literaria, "exprese", no obstante, la vida. Dicho de otro modo: ¿qué relación hay entre lenguaje y vida?

A) Por más que la noción de expresión apareciera en su momento asociada a la intimidad psicológica del poeta, no hace falta insistir demasiado en que la existencia de cualquier persona abarca muchísimo más que dicha intimidad. Es más, probablemente haya que darle la vuelta al presupuesto desde el cual se plantea la distinción "objetivo"/"subjetivo". La distinción resulta pertinente en el ámbito del conocimiento, que para ser tal debe prescindir de lo subjetivo, es decir, de aquello que sea particular de quien pretende conocer. Pero nuestra relación con el mundo ¡no es primordialmente de conocimiento! Nuestra existencia ¡no es la de un sujeto cognoscente! Siguiendo a Heidegger, podemos decir que somos "seres-de-mundo", pues que el mundo es nuestro medio, nuestro elemento, como es el agua para el pez o el aire para el ave. Estamos en todo momento abiertos al mundo, y por mundo entendemos aquí no sólo todo lo que hay, sino ese "todo lo que hay" también en su significación, esto es, por lo que hace al sentido, que, como Nietzsche nos advirtió, se nos dan inseparablemente: "No hay hechos, sólo interpretaciones". El mundo, para nosotros, es trama significante que articula la realidad. Por eso el lenguaje, articulación por antonomasia, forma parte no sólo de nuestra existencia, sino también del mundo. Dicho a la inversa, no hay mundo que no forme parte de nuestra existencia.

Es la convicción heredada de que el lenguaje refleja el mundo lo que nos impide atender a la experiencia básica de que si el lenguaje funciona es porque está perfectamente integrado en el mundo: entender algo es plantarse de golpe en ese algo, ver aquello de lo que se habla, no la fantasiosa e inexistente operación de pasar de un significante a un significado. El que esté perfectamente integrado tampoco significa que todo en esta vida tenga sus palabras ya dispuestas. Ya sabemos que no. Por eso puede el lenguaje descubrirnos cosas que no sabíamos y la literatura "poner al descubierto incluso nuevas posibilidades de ser" (Heidegger 1988: 375-376). Es como si el mundo estuviera circulado de palabras que lo hacen humano a la existencia y, así, hallar expresiones nuevas es descubrir espacios desconocidos. 
De ahí el que la expresión de las vivencias no tenga por qué ser "subjetiva" en el sentido de íntima. Será personal, como, por demás, lo es toda vivencia. Si, por otro lado, tenemos en cuenta que el lenguaje es presencia de la sociedad en el particular, medio fundamental por el que se instila lo social en el individuo, habrá que reconocer la posibilidad de que se dé una expresión no subjetiva del mundo a través de las vivencias del escritor. Esto nos parece que es lo que de modo explícito practicaba Kertész en Sin destino.

B) Hablábamos de una diferencia substancial entre vida y lenguaje. Por otro lado, insistimos en que el lenguaje es un modo de ser de la existencia. ¿Cómo es posible, entonces, la expresión? Para entender esto hay que considerar el lenguaje de otra manera que la que es habitual. Y la que es habitual se basa en el uso cotidiano del lenguaje. Usamos el lenguaje cotidiano, efectivamente, como un instrumento, para referirnos al mundo que ya está cartografiado: ahí sí que parece que el lenguaje representa la realidad, y en la medida en que la representa, se puede pensar que la refleja, y que, por lo tanto, el lenguaje fuera otra cosa que la realidad, ¡como si ésta pudiera existir para nosotros sin el lenguaje!

Mas el lenguaje cotidiano no nos da la medida de lo que la palabra puede. De hecho, el verdadero pensamiento y la literatura, en fin, lo пиеvо no pueden entenderse según dicho uso. Tanto Heidegger como Merleau-Ponty insistirán en distinguir otra posibilidad del lenguaje, la que propiamente nos muestra lo que éste hace: su carácter, digamos, creativo. Merleau-Ponty distingue entre lenguaje hablante-langage parlant-y lenguaje hablado -langage parlé-. El lenguaje hablado es el lenguaje ya establecido, el lenguaje en su uso cotidiano. Heidegger lo llamará Gerede o 'hablilla', y le contrapondrá un lenguaje al que también se puede denominar "hablante", sprechend.

Cuando decimos aquí “creativo" ya sabemos que la creación no es partir de la nada; crear es inventar pero a la vez descubrir, o descubrir pero inventando. Acudamos a la útil cobardía del ejemplo: Sin destino nos descubre Auschwitz inventado una manera de hacérnoslo presente. No había antes un lenguaje preparado para representar Auschwitz (y por eso se suele decir que es irrepresentable), pero se puede hacer que el lenguaje nos acerque a ello. Realmente, en lo que de nuevo ofrece, el escritor inventa ${ }^{25}$, mas lo hace de tal manera que lo inventado se adecua a la experiencia y cuando lo hace con justeza acaba pareciendo que efectivamente así era, ahí estaba, esperando la mirada que lo descubriera. A ese descubrir inventando le llamó Nietzsche, y Heidegger tras él, interpretar. Dicho en alemán, interpretar, Auslegen, es también 'ex-poner', 'poner a la vista', sacar a la luz lo que estaba oculto, invisible. Claro está, ambos filósofos hablan de interpretar porque entienden que la vida, la existencia son vida y existencia, y sólo vicariamente se dejan verter en lenguaje. En los inicios, pues, "interpretar" dice de la relación entre ser lingüístico y realidad muda. Pero estamos hechos de tal manera que esa realidad muda nos "habla" en su silencio: sólo interpretándola es lo que es para nosotros.

\footnotetext{
25 Nietzsche, en un fragmento de Aurora, §119, dice: "Toda nuestra llamada conciencia no es más que el comentario más o menos imaginario de un texto desconocido, quizás incognoscible, y, sin embargo, sentido. [...] ¿Qué son, pues, nuestra vivencias? Es mucho más lo que ponemos en ellas que lo que en ellas hay. ¿No habría que decir, tal vez, que en ellas propiamente no hay nada? ¿Que tener vivencias es inventar?” (Nietzsche 1881: 114. Traducción, mía: J. A.)
} 
Volvamos a la palabra hablada. En ella entrevé Merleau-Ponty "el fantasma de un lenguaje puro": "nos parece que [la expresión] alcanza su vértice cuando señala inequívocamente acontecimientos, estados de cosas, ideas o relaciones, ya que en estas circunstancias no deja nada que desear, no contiene más que lo que muestra, nos hace deslizarnos hacia el objeto que designa" (Merleau-Ponty 1971: 25). El buen uso del lenguaje cotidiano, la comunicación lograda produce ese efecto: el lenguaje se borra a sí mismo y nos deja solos con las cosas. Y cuando uno dice "cosas", dice también pensamientos, sentimientos, etc. De ahí el que se llegue a pensar que la significación está en la realidad o en el pensamiento, de los cuales el lenguaje sería sólo signo o transparente abreviatura. El mito del lenguaje, la manera como durante tanto tiempo se lo ha pensado, acabaría en que todo fuera «como si no hubiese habido lenguaje» (Merleau-Ponty 1971: 32).

Mas ya hemos visto que esa manera de concebir el lenguaje y su trato con la realidad no nos permite entender lo nuevo, y, además, ése no es el modo como el lenguaje funciona, como se vive el lenguaje. La consideración del lenguaje literario o poético nos lleva a entender de otro modo el ser del lenguaje. Se introduce una doble corrección respecto de la concepción habitual: 1) si en la concepción mimética el lenguaje aparece separado de la realidad, reflejándola, en la hermenéutica, por el contrario, el lenguaje es parte de la vida, está integrado en el mundo; 2) como compensación, en la concepción mimética el lenguaje es homólogo de la realidad, esto es, la realidad posee por sí significación, que el lenguaje transportaría; en la hermenéutica el lenguaje es otro que la vida, y si la puede expresar es por estar entreverando la vida, por ser elemento suyo.

Pensemos en la lectura, en la escritura.

Leemos Sin destino, y si entramos en la narración, si la lectura nos engancha, «estamos» en Auschwitz. Ya sabemos que no estamos en Auschwitz, probablemente no habríamos regresado, mas sí entramos en el mundo de Auschwitz (¿cómo llamarlo, si no?). Kertész nos decía que "el campo de concentración únicamente puede imaginarse como texto literario, no como realidad» (Kertész 2004: 222). Entramos en el mundo imaginado de Auschwitz, porque Kertész ha sabido imaginarlo en palabras. (Y aquí quizá habría que precisar: imaginar en palabras no es imaginar, es decir, ponerlo en imágenes. Hemos de desprendernos definitivamente del ut pictura poesis.) Y nuestro entrar en Auschwitz no es sólo volver a visitarlo, repetir los demás textos leídos sobre el tema, las películas vistas; es, gracias a la manera como Kertész lo concibe, vivir el sinsentido y a la vez el sentido (del sinsentido vivido), es reordenar las relaciones entre individuos y campo o mundo, degustar el sabor de la lógica en tiempos de hambre, etc. Entrar en Auschwitz supone no sólo entender más de Auschwitz, sino transformarse uno mismo: sus experiencias previas, categorizaciones, lógica, estilo. El mundo del sentido propio adquiere una nueva forma, somos otro.

La obra original, a través de la lectura que de ella hacemos, va operando en nosotros una transformación cuya meta final es el haber entendido, el habérnoslas de otra manera con el mundo. Y, sí, al final parece que las palabras sobraran, una vez hemos llegado. Mas son las palabras, el texto literario en su materialidad significativa, las que poseen ese poder transformador.

El lenguaje hablado sería el que el lector lleva consigo al empezar a leer; el hablante "es la interpelación que el libro dirige al lector no prevenido" (MerleauPonty 1971: 38), operando en él esa transformación a que aludíamos, segregando una 
significación nueva que es la comprensión incorporada. En Lo visible y lo invisible, la obra que Merleau-Ponty estaba escribiendo cuando murió en 1961, el lenguaje hablante, "operante", es "ese lenguaje-cosa [que] hace que afloren todas las relaciones profundas de lo vivido donde se ha formado, y es el de la vida y la acción, aunque también el de la literatura y la poesía" (1970: 159)

Si el lenguaje opera así en la simple lectura, ¡qué poder no tendrá en la escritura! Podemos entender el lenguaje como esa planta que arraigada en la existencia saca a la luz en su crecimiento la textura de la tierra en que brota; podemos también, con Heidegger, pretender que las palabras son manantiales... ${ }^{26}$ Sea como fuere, el caso es que antes de la expresión, lo que había era mudo: la vivencia, ya lo hemos dicho, está hecha de silencio, de la materia de la vida; y ésta, sí, puede buscar la expresión pero no posee una significación previa a la que la palabra le confiere. Lo que hay antes de la expresión es una intención significante que lleva a hablar, a escribir. Mas dicha intención significante no es más que un vacío que busca la palabra en que encarnar. Expresar es tomar conciencia.

La intención significante se da un cuerpo y se conoce a sí misma al buscarse un equivalente del sistema de significados disponibles que la lengua que hablo y el conjunto de los escritos y de la cultura cuyo heredero soy representan. Se trata, para ese deseo mudo que es la intención significante, de realizar una determinada disposición de los instrumentos ya significantes o de los significados ya parlantes [...] que lleve a cabo en el que habla o el que escribe el anclaje del significado inédito en los significados ya disponibles. [...] Yo expreso cuando, utilizando todos esos instrumentos ya parlantes, les hago decir algo que no han dicho nunca. (Merleau-Ponty 1964: 108).

Cuando escribimos, cuando propiamente pensamos, no sabemos lo que vamos a pensar, va surgiendo, y según surge, vamos corrigiendo, acomodando las palabras que nos vienen a las mientes a lo que "queremos decir". ¿Estaba dado de antemano lo que queríamos decir? Sí, y no. Algo había que nos permite ir acomodando las ideas y las palabras a lo intuido. Mas no estaba formulado en palabras, esto es, no estaba formulado. Son las propias palabras que vamos produciendo las que, por su relación ya establecida con las cosas y con los significados, nos van guiando. Por eso, al final queda siempre la sensación, aun con la mejor de las expresiones, que lo que se quería decir era eso y, a la vez, no lo era. Dicho en las palabras de Kertész: la literatura quiere imitar a la vida, y la imita, hasta la realza, mas no es vida. De ahí el que nunca se acabe de decir lo que se quería.

Es cierto que al final, cuando se ha logrado transmitir un significado, parece que estaba ahí, antes, esperándonos. Pero tal el efecto de la singularidad del lenguaje. Así como la vida se caracteriza frente a lo lingüístico por su vivacidad, por su realidad, como diría Ortega, por su ejecutividad, que le confiere una solidez, una intensidad distintiva, así lo lingüístico produce la ilusión de haber estado contenido en la vida, cuando en realidad no es sino su fruto, el resultado de un deseo, una pasión y un trabajo vertidos en una obra que acaba objetivando el vacío primero. Tener una idea no

26 "Die Worte sind Brunnen, denen das Sagen nachgräbt, Brunnen, die je und je neu zu finden und zu graben sind, leicht verschüttbar, aber bisweilen auch unversehens quillend" (Heidegger 1984: 89) [“Las palabras son manantiales en cuya busca el decir perfora la tierra, que una y otra vez hay que hallar y perforar de nuevo, fáciles de cegar, aunque en ocasiones brotan también cuando menos se espera." Traducción, mía: J. A.] 
es tenerla frente a uno a la vista, como la falsa imagen de la conciencia-escenario nos invita a creer, es sencillamente saber organizar discursos coherentes en torno a ella, lo que, obviamente, es el resultado de un práctica, el hábito de vivir en la palabra.

Ese desconocimiento que habita al hablante, al escritor que hace algo más que repetir lo ya sabido, lo ya dicho, es lo que nos viene a decir que no somos de una pieza. Ya la presencia del lenguaje en nosotros es nota de la multiplicidad, incluso presencia de los demás en uno mismo. El desconocimiento que sale a la luz en el fenómeno de la escritura hablante nos señala a lo inconsciente, a las raíces ignotas de la conciencia, en definitiva, a la existencia; en cualquier caso introduce una quiebra en la unidad imaginaria del individuo, apunta a esa diferencia radical con que Kertész se encontraba una y otra vez, y cuya matriz podemos entender ahora que está, efectivamente, en la otredad de la existencia o de la vida respecto del lenguaje, por más que éste le sea consubstancial. Por ello, dar expresión a la vida no sólo es revivir, sino ir apropiándose de ella y, así, ir haciéndose otro: "[la existencia efectiva] consiste en ser activamente aquello que somos por azar, en establecer esa comunicación con los demás y con nosotros mismos" (Merleau-Ponty 1977: 77). La vida nos es y la somos.

\section{OBRAS CITADAS}

Aguiar e Silva, Vítor Manuel de. 2001. Teoría de la literatura. Versión española de V. García Yebra. $2^{\mathrm{a}}$ ed. Madrid: Gredos.

Bech, Josep Maria. 2005. Merleau-Ponty. Una aproximación a su pensamiento. Barcelona: Anthropos.

Gadamer, Hans-Georg. 1996. Verdad y método. Fundamentos de una hermenéutica filosófica. Trad. de A. Agud y R. de Agapito. $6^{a}$ ed. Salamanca: Sígueme.

García Leal, José. 2002. Filosofía del arte. Madrid: Síntesis.

Heidegger, Martin. 1984. Was heisst Denken? $4^{\mathrm{a}}$ ed. Tübingen: Niemeyer.

—. 1988. Prolegomena zur Geschichte des Zeitbegriffs. Gesamtausgabe, Bd. 20. $2^{\mathrm{a}}$ ed. Frankfurt am Main: Klostermann. (Hay versión española de J. Aspiunza. Madrid: Alianza. 2006.)

- 1989. Nietzsche I. $5^{\text {a }}$ ed. Pfullingen: Neske.

Kertész, Imre. 2001a. Sin destino. Trad. de J. Xantus. Barcelona: Acantilado.

- 2001b. Kaddish por el hijo no nacido. Trad. de A. Kovacsics. Barcelona: Acantilado.

—. 2002a. Yo, otro. Crónica del cambio. Trad. de A. Kovacsics. Barcelona: Acantilado.

- 2002b. Un instante de silencio en el paredón. El Holocausto como cultura. Trad. de A. Kovacsics. $2^{\mathrm{a}}$ ed. Barcelona: Herder.

— 2003. Fiasco. Trad. de A. Kovacsics. Barcelona: Acantilado.

- 2004. Diario de la galera. Trad. de A. Kovacsics. Barcelona: Acantilado.

—. 2005a. La bandera inglesa. Trad. de A. Kovacsics. Barcelona: Acantilado.

—. 2005b. "Dossier K. Eine Ermittlung. Erstveröffentlichung”. Du 757: 52-62.

2006. Dossier K. Eine Ermittlung. Trad. de K. Schwamm. Hamburgo: Rowohlt.

Mann, Thomas. 2001. La voluntad de ser feliz y otros relatos. Trad. de R. Sala. Barcelona: Alba.

Merleau-Ponty, Maurice. 1964. Signos. Trad. de C. Martínez y G. Oliver. Barcelona: Seix-Barral. 1970. Lo visible y lo invisible. Trad. de J. Escudé. Barcelona: Seix-Barral. 
— 1971. La prosa del mundo. Versión española de F. Pérez Gutiérrez. Madrid: Taurus.

— 1977. Sentido y sinsentido. Trad. de N. Comadira. Barcelona: Península.

Nietzsche, Friedrich. 1881. Morgenröte. Kritische Gesamtausgabe, Bd. 3. München/Berlin: dtv/de Gruyter.

- 1975. La genealogía de la moral. Trad. de A. Sánchez Pascual. $2^{\text {a }}$ ed. Madrid: Alianza.

—. 1980. El nacimiento de la tragedia. Trad. de A. Sánchez Pascual. $5^{\mathrm{a}}$ ed. Madrid: Alianza.

—. 1988a. Nachgelassene Fragmente 1885-1887. Kritische Gesamtausgabe, Bd. 12. München/ Berlin: dtv/de Gruyter.

—. 1988b. Nachgelassene Fragmente 1880-1882. Kritische Gesamtausgabe, Bd. 9. München/ Berlin: dtv/de Gruyter.

—. 2006. Fragmentos póstumos (1885-1889). Vol. IV. Ed. española de D. Sánchez Meca. Trad. de J. L. Vermal y J. B. Llinares. Madrid: Tecnos.

Sánchez Meca, Diego. 1989. En torno al superhombre. Nietzsche y la crisis de la modernidad. Barcelona: Anthropos. 